\title{
Validated Spectrophotometric Methods for the Simultaneous Determination of Ciprofloxacin Hydrochloride and Metronidazole in Tablets
}

\author{
Marianne Alphonse Mahrouse* and Ehab Farouk ElKady \\ Pharmaceutical Chemistry Department, Faculty of Pharmacy, Cairo University; Kasr El-Aini St., Cairo 11562, Egypt. \\ Received August 3, 2011; accepted September 9, 2011; published online September 27, 2011
}

\begin{abstract}
A binary mixture of ciprofloxacin hydrochloride (CIP) and metronidazole (MET) was determined by five simple and accurate methods, without prior separation. In the first method, CIP was determined by second derivative spectrophotometric method $\left({ }^{2} \mathrm{D}\right)$ by measuring the amplitude at $282 \mathrm{~nm}$ (zero ordinate value of MET). On the other hand, the determination of MET was based on isosbestic point technique, where the total content of the mixture was determined at $294.5 \mathrm{~nm}$ (isosbestic point), then the content of MET could be calculated by subtraction. The second method was first derivative ratio spectrophotometric method $\left({ }^{1} \mathrm{DD}\right)$ where the total amplitude at 261 and $285 \mathrm{~nm}$ and the amplitude at $295.5 \mathrm{~nm}$ were selected to simultaneously determine CIP and MET in binary mixture, respectively. The third method was based on dual wavelength analysis, in which two wavelengths were selected, at which the absorbances of the other component were the same. The fourth method depends on using $Q$-analysis method (absorbance ratio) which involves the formation of $Q$-absorbance equation using the respective absorptivity values at $294.5 \mathrm{~nm}$ (isosbestic point) and $281.5 \mathrm{~nm}$ ( $\lambda_{\max }$ of CIP). The fifth method is partial least-squares (PLS) chemometric technique for determination of CIP and MET. The developed methods were successfully applied to the analysis of CIP and MET in laboratory prepared mixtures and tablets with good recoveries and their validation was carried out following the International Conference on Harmonization (ICH) guidelines. The results obtained were statistically compared with each other showing no significant difference with respect to accuracy and precision.
\end{abstract}

Key words ciprofloxacin; metronidazole; spectrophotometry; chemometry

Ciprofloxacin (CIP, Fig. 1a) [1-cyclopropyl-6-fluoro-1,4dihydro-4-oxo-7-(piperazinyl)-quinolone-3-carboxylic acid] belongs to the second generation of fluoroquinolone antibacterial agents. These quinolones are effective against Grampositive and Gram-negative bacteria through inhibiting bacterial DNA gyrase (topoisomerase), the enzyme responsible for maintaining the superhelical twists in the bacterial DNA, leading to inhibition of bacterial DNA synthesis. ${ }^{1)}$ Similar to other fluoroquinolones, CIP has shown clinical efficacy in the treatment of a wide range of systemic infections such as urinary tract, respiratory, gastrointestinal and cutaneous infections. Because of its low toxicity, very wide spectrum of antibacterial effect and low ability to cause bacterial resistance, CIP has been widely used in clinical practice. ${ }^{2)}$ Metronidazole (MET, Fig. 1b) is used as an antiprotozoal, antiamebic and antibacterial drug. ${ }^{3)}$ It is chemically designated as 2methyl-5-nitroimidazole-1-ethanol. Since CIP has a reduced activity against anaerobic pathogens, CIP and MET are coformulated together in pharmaceutical dosage forms for the treatment of mixed aerobic/anaerobic infections. ${ }^{4)}$

A survey of literature has revealed several analytical methods for the determination of CIP in pharmaceutical dosage

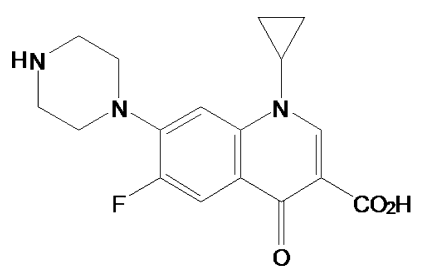

a

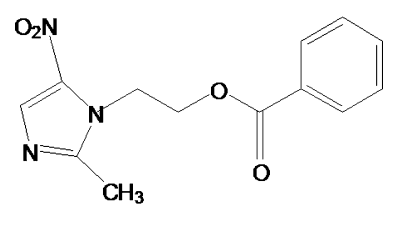

$\mathrm{b}$
Fig. 1. Chemical Structures of Ciprofloxacin (a) and Metronidazole (b) form and biological fluids, including spectrophotometry, ${ }^{5-8)}$ spectrofluorimetry, ${ }^{9-11)}$ HPLC, ${ }^{12-16)}$ capillary electrophoresis ${ }^{17,18)}$ and HPTLC. ${ }^{19)}$ CIP in admixtures with MET and ampicillin has been determined by NMR. ${ }^{20)}$ Recently, HPLC methods either with fluorescence detection or coupled with mass spectrometry (LC/MS) for determination of ciprofloxacin in human plasma ${ }^{21,22)}$ have also been published.

MET has been determined by several methods involving spectrophotometry ${ }^{23-26)}$ and HPLC. ${ }^{27-32)}$ MET in intravenous admixture with CIP was determined by first-derivative spectrophotometry ${ }^{33)}$ and LC. ${ }^{34)}$ Literature reports only one article for the simultaneous determination of CIP and MET in tablet form by the same authors of the present work. In this article, a reversed phase ion-pair HPLC and TLC densitometry have been adopted for the simultaneous determination of both drugs in tablets. ${ }^{35)}$ However, due to lack of such equipments in many resources-limited countries and the high costs of HPLC grade solvents and columns, alternative methods are needed to facilitate and increase the speed of analysis, with relatively few costs. To the best of the authors' knowledge, no previous article concerning simultaneous spectrophotometric determination of the two drugs was published. Spectrophotometry continues to be very popular, because of its simplicity, versatility and low cost. Therefore, the aim of the present work was to develop and validate different UV spectrophotometric and chemometric techniques for the simultaneous determination of CIP and MET in tablets without previous separation. Both derivative and derivative ratio spectrophotometry are useful technique for resolving two overlapping spectra and eliminating matrix interferences in the assay of multi-component mixtures. ${ }^{36,37)}$ Besides, isoabsorptive spectrophotometry and the newly developed dual wavelength and $Q$ analysis methods have proved to be power- 
ful techniques for determination of drugs. ${ }^{38-44)}$

In recent years, multivariate calibrations, such as Partial Least-Squares (PLS) have been applied to the analysis of the analytical data obtained in all the instrumentations. The same methods have been applied to the simultaneous spectrophotometric determination of drugs in the pharmaceutical formulations containing two or more compounds with overlapping spectra. ${ }^{45,46)}$ Besides, the chemometric calibration methods have been used extensively in quantitative spectral analysis to get selective information from unselective data. Currently, PLS has become the standard for multivariate calibration because of the quality of the calibration models, the easiness of its implementation and the availability of software. ${ }^{47-49)} \mathrm{Be}-$ sides, the errors of a calibration models are minimized by measuring the absorbance values at many points in the wavelength range of the zero-order and derivative spectra. This work presents PLS as a useful technique to resolve interference between CIP and MET in their zero order spectra.

\section{Experimental}

Chemicals and Reagents Pharmaceutical grade CIP and MET were supplied by MINAPHARM Pharmaceuticals (Cairo, Egypt) and certified to contain 100.70 and $99.44 \%$, respectively. Ciprodiazole ${ }^{\mathbb{B}}$ tablets, Batch No. AKE2558, labeled to contain $500 \mathrm{mg}$ CIP and $500 \mathrm{mg}$ MET per one tablet were manufactured and supplied by MINAPHARM Pharmaceuticals (Cairo, Egypt). Methanol (CHROMASOLV ${ }^{\circledR}$ grade) was obtained from SigmaAldrich Chemie GmbH (Steinheim, Germany).

Equipment A double beam UV/visible spectrophotometer (JENWAY, United Kingdom) model 6800 with quartz cell of $1 \mathrm{~cm}$ pathlength, connected to Samsung compatible computer was used for the ${ }^{2} \mathrm{D}$, isosbestic, ${ }^{1} \mathrm{DD}$, dual wavelength and $Q$ analysis methods. The software was JENWAY model 6800 Spectrophotometer Flight Deck. The spectral band width was $1.5 \mathrm{~nm}$ with wavelength scanning speed of $400 \mathrm{~nm} \mathrm{~min}^{-1}$.

For the PLS- assisted spectrophotometric method, a double beam UV/visible spectrophotometer (Shimadzu UV-1650 PC, Kyoto, Japan) connected to an IBM compatible computer and supported with UVPC soft ware version 2.21 (Shimadzu) was used. PLS was performed using Matlab ${ }^{\mathrm{TM}}$, Version 7 and PLS-Toolbox 2.0.

Standard Solutions. Stock Solutions CIP and MET stock solutions $\left(1 \mathrm{mg} \mathrm{ml}^{-1}\right)$ were prepared by weighing accurately $100 \mathrm{mg}$ of each powder into two separate $100 \mathrm{ml}$ volumetric flasks, sonicating to dissolve in an ultrasonic bath for $5 \mathrm{~min}$ then completing to volume with methanol. Light protected volumetric flasks were used in case of MET solutions.

Working Solutions Four milliliters of each stock solution were accurately transferred into two separate $100 \mathrm{ml}$ volumetric flasks and completed to volume with methanol to get a final concentration of $40 \mu \mathrm{g} \mathrm{ml}^{-1}$. Light protected volumetric flasks were used in case of MET solutions.

Laboratory Prepared Mixtures Accurate aliquots in the ranges equivalent to either $(50-150 \mu \mathrm{g}),(50-130 \mu \mathrm{g})$ or $(20-70 \mu \mathrm{g})$ of each CIP and MET in case of $\left({ }^{2} \mathrm{D}\right.$, isosbestic and dual wavelength methods), $\left({ }^{1} \mathrm{DD}\right.$ and $Q$ analysis methods) and PLS method, respectively, were transferred from working solutions $\left(40 \mu \mathrm{g} \mathrm{ml}^{-1}\right)$ into two separate series of $10 \mathrm{ml}$ volumetric flasks and completed to volume with methanol and mixed well.

Sample Preparation Twenty tablets were accurately weighed and powdered in a mortar. A quantity of the powdered tablets equivalent to $100 \mathrm{mg}$ CIP and MET was transferred into a $100 \mathrm{ml}$ volumetric flask, then $50 \mathrm{ml}$ methanol were added. The solution was sonicated for $5 \mathrm{~min}$, completed to $100 \mathrm{ml}$ with the same solvent, mixed well and filtered on dry funnel and dry filter paper discarding the first few milliliters. Sample solution of concentration equivalent to $\left(1 \mathrm{mg} \mathrm{ml}^{-1}\right)$ of each drug was obtained.

Procedure. ${ }^{2} \mathrm{D}$ and Isosbestic Methods Linearity: Aliquots from CIP and MET working solutions $\left(40 \mu \mathrm{g} \mathrm{ml}^{-1}\right)$ equivalent to $(30-140 \mu \mathrm{g})$ were transferred into two separate sets of $10 \mathrm{ml}$ volumetric flasks and completed to the mark with methanol. The zero order absorption spectra were recorded for both drugs using methanol as blank, then the amplitude of the minimum at $282 \mathrm{~nm}$ (zero ordinate value of MET), using smoothing factor 20 for CIP and the absorbance at $294.5 \mathrm{~nm}\left(A_{\text {iso }}\right)$ for CIP and MET were measured. Two calibration curves were constructed for CIP and MET relating either the amplitude or the absorbance, respectively, at the selected wavelengths to the corresponding drug concentrations and the regression equations were com- puted.

Assay of Laboratory Prepared Mixtures: Amplitudes of the spectra of laboratory prepared mixtures at $282 \mathrm{~nm}$ corresponding to the contents of CIP only and absorbances at $294.5 \mathrm{~nm}\left(A_{\text {iso }}\right)$ corresponding to the total content of CIP and MET in the mixture were measured. The concentration of CIP alone and the total concentration of the two drugs were calculated from their corresponding regression equations, then by subtraction of CIP concentration from the total mixture concentration, the actual concentration of MET in the mixture was obtained.

${ }^{1}$ DD Method Linearity: The absorption spectra of standard solutions of CIP $\left(2.4-16 \mu \mathrm{g} \mathrm{ml}^{-1}\right)$ and MET $\left(4-16 \mu \mathrm{g} \mathrm{ml}^{-1}\right)$ were recorded against a blank of methanol and stored in the computer. The stored spectra of CIP and MET were divided by the stored spectrum of MET $\left(4 \mu \mathrm{g} \mathrm{ml}^{-1}\right)$ for determination of CIP and by the stored spectrum of CIP $\left(3 \mu \mathrm{g} \mathrm{ml}^{-1}\right)$ for the determination of MET, respectively. Then, the first derivative of the above ratio spectra were obtained and smoothed at $\Delta \lambda=15$ and 10, for CIP and MET, respectively. The total amplitudes of the first derivative of the ratio spectra at the minimum at $261 \mathrm{~nm}$ and the maximum at $285 \mathrm{~nm}$ and that of the minimum at $295.5 \mathrm{~nm}$ were plotted against the corresponding concentrations of $\mathrm{CIP}$ and MET, respectively, and regression equations were computed.

Assay of Laboratory Prepared Mixtures: The same procedure mentioned under linearity was applied in order to determine CIP and MET in the laboratory prepared mixtures. The concentrations of the two drugs were calculated from the computed regression equation.

Dual Wavelength Method Linearity: Aliquots equivalent to (30$160 \mu \mathrm{g})$ of CIP and MET were transferred separately from their corresponding stock solutions $\left(40 \mu \mathrm{g} \mathrm{ml}^{-1}\right)$ into two separate series of $10 \mathrm{ml}$ volumetric flasks, completed to volume with methanol and scanned in the region of $200-400 \mathrm{~nm}$ using methanol as blank. The spectrum of MET shows identical absorbances at $281.5 \mathrm{~nm}(\lambda 1)$ and $335.5 \mathrm{~nm}(\lambda 2)$ while that of CIP reveals same absorbances at $313 \mathrm{~nm}(\lambda 3)$ and $324 \mathrm{~nm}(\lambda 4)$, therefore the wavelengths at $(\lambda 1, \lambda 2)$ and $(\lambda 3, \lambda 4)$ were selected for the analysis of CIP and MET, respectively. CIP was determined by plotting the difference in absorbance at 281.5 and $335.5 \mathrm{~nm}$ (difference is zero for MET) against its corresponding concentration. Similarly, for determination of MET, the difference in absorbance at 313 and $324 \mathrm{~nm}$ (difference is zero for CIP) was plotted against the corresponding concentration. The concentrations of the two drugs were calculated each from the corresponding regression equation.

Assay of Laboratory Prepared Mixtures: Zero order absorption spectra of different laboratory prepared mixtures of CIP and MET were recorded. Then, the differences in absorbances at $281.5,335.5 \mathrm{~nm}$ and at $313,324 \mathrm{~nm}$ were measured and the concentrations of the drugs were calculated from the corresponding regression equations.

$\boldsymbol{Q}$ Analysis Method (Absorbance Ratio) Linearity: Standard solutions containing (3-10 $\mu \mathrm{g} \mathrm{ml}^{-1}$ ) each of CIP and MET were prepared separately using methanol. The absorption spectra of the prepared solutions were recorded in the range of $200-400 \mathrm{~nm}$ and the absorbance values at $281.5 \mathrm{~nm}\left(\lambda_{\max }\right.$ of CIP) and $294.5 \mathrm{~nm}\left(\lambda_{\text {iso }}\right)$ were measured from which the absorptivity values for both drugs at the selected wavelengths were calculated and the average values were taken. The method employs $Q$ values and the concentrations of the studied drugs in the prepared solutions were determined by using the following equations:

$$
\begin{aligned}
C_{x} & =\frac{Q_{m}-Q_{y}}{Q_{x}-Q_{y}} \times \frac{A}{A_{x}} \\
C_{y} & =\frac{Q_{m}-Q_{x}}{Q_{y}-Q_{x}} \times \frac{A}{A_{y}}
\end{aligned}
$$

where $C_{x}$ and $C_{y}$ are the concentrations of CIP and MET in $\mu \mathrm{g} \mathrm{ml}^{-1}$, respectively; $Q_{m}$ is the absorbance of sample at $\lambda_{281.5}$ /absorbance of sample at $\lambda_{2945} ; Q_{x}$ is the absorptivity of CIP at $\lambda_{2815}$ /absorptivity of CIP at $\lambda_{294.5} ; Q_{y}$ is the absorptivity of MET at $\lambda_{281.5} /$ absorptivity of MET at $\lambda_{294.5} ; A_{x}$ is the absorptivity of CIP at $\lambda_{294.5} ; A_{y}$ is the absorptivity of MET at $\lambda_{294.5} ;$ and $A$ is the absorbance of the sample at $\lambda_{294.5}$.

Assay of Laboratory Prepared Mixtures: The absorbances of the laboratory prepared mixtures at $\lambda_{281.5}$ and $\lambda_{294.5}$ were recorded, absorptivities were calculated and substituted in the equations mentioned under linearity, in order to obtain the concentration of both drugs.

PLS Technique Construction of the Training Set: Twelve binary mixtures of CIP and MET were prepared by transferring different volumes of their working solutions $\left(40 \mu \mathrm{g} \mathrm{ml}^{-1}\right)$ into a series of $10 \mathrm{ml}$ volumetric flasks, Table 1 . The absorbances of these mixtures were measured between 280 and $330 \mathrm{~nm}$ at $0.2 \mathrm{~nm}$ intervals against methanol as a blank. 
Table 1. The Concentrations of Different Mixtures of CIP and MET Used in the Training Set

\begin{tabular}{ccc}
\hline \hline & \multicolumn{2}{c}{ Claimed taken $\left(\mu \mathrm{g} \mathrm{ml}^{-1}\right)$} \\
\cline { 2 - 3 } Sample No. & CIP & MET \\
\hline 1 & 1 & 0.8 \\
2 & 1 & 1.0 \\
3 & 1 & 1.2 \\
4 & 3 & 2.8 \\
5 & 3 & 3.0 \\
6 & 3 & 3.2 \\
7 & 5 & 4.8 \\
8 & 5 & 5.0 \\
9 & 5 & 5.2 \\
10 & 8 & 7.8 \\
11 & 8 & 8.0 \\
12 & 8 & 8.2 \\
\hline
\end{tabular}

Construction of PLS Model: Calibration or regression was obtained by using the absorbance data matrix and concentration data matrix for prediction of the unknown concentrations of CIP and MET in their binary mixtures. The training set absorbance and concentration matrices together with PLS-toolbox 2.0 software were used for calculations.

Selection of the Optimum Number of Factors to Build the PLS Model: To select the optimum number of factors in the PLS algorithms, a cross-validation method leaving out one sample at a time ${ }^{50)}$ was employed using calibration set of 12 calibration spectra. PLS calibration on 11 calibration spectra was performed and, using this calibration, the concentration of the sample left out during the calibration process was predicted. This process was repeated 12 times until each training sample had been left out once. The predicted concentrations of the components in each sample were compared with the actual concentrations in this calibration samples and Root-Mean-Square Error of Cross-Validation (RMSECV) was calculated for each method. It indicates both of the precision and accuracy of predictions. It was recalculated upon addition of each new factor to the PLS model.

$$
\text { RMSECV }=\sqrt{\frac{\text { PRESS }}{n}}
$$

where PRESS is the predicted residual error sum of squares and $n$ is the number of calibration samples. ${ }^{51)}$

$$
\text { PRESS }=\sum\left(Y_{\text {pred }}-Y_{\text {true }}\right)^{2}
$$

where $Y_{\text {pred }}$ and $Y_{\text {true }}$ are predicted and true concentrations in $\mu \mathrm{g} \mathrm{ml}^{-1}$, respectively.

Visual inspection was used for selecting the optimum number of factors. Three factors were found suitable for PLS method.

Assay of Ciprodiazole Tablets For the determination of the examined drugs in ciprodiazole tablets, the sample solution was diluted to prepare a solution equivalent to $40 \mu \mathrm{g} \mathrm{ml}^{-1}$ of each CIP and MET. Different aliquots were separately transferred into $10 \mathrm{ml}$ volumetric flasks and diluted with methanol. The procedure under linearity for each method was followed. The validity of the methods was assessed by applying the standard addition technique.

\section{Results and Discussion}

The main task of this work was to establish and validate simple, sensitive and accurate spectrophotometric methods as substitutes for the HPLC and TLC methods reported for the simultaneous determination of CIP and MET in bulk powder and pharmaceutical dosage form with satisfactory precision for good analytical practice (GAP). In addition, statistical comparison and evaluation of the efficiency of the developed methods for the determination of the studied drugs were of interest.

Optimization of Conditions for ${ }^{2} \mathrm{D}$, Isosbestic, ${ }^{1} \mathrm{DD}$, Dual Wavelength and $Q$ Analysis Spectrophotometric Methods. ${ }^{2} D$ and Isosbestic Methods Figure 2 reveals se-

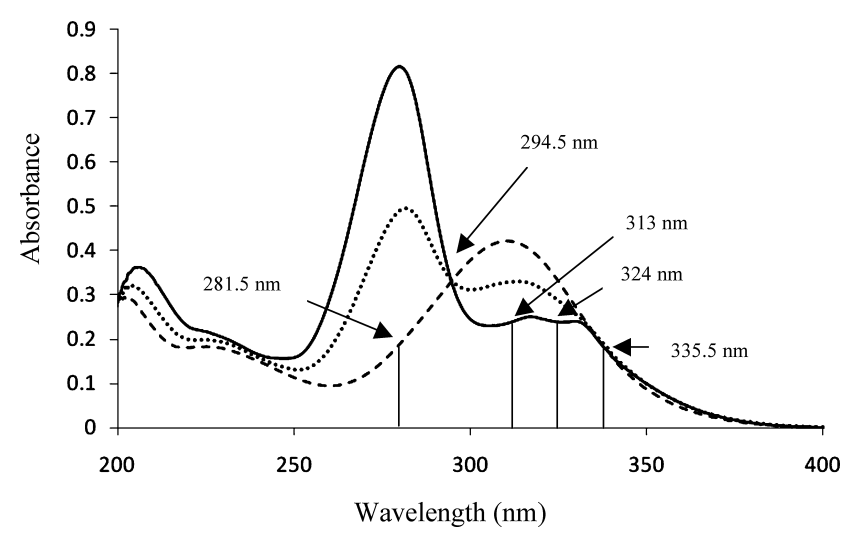

Fig. 2. Zero-Order Absorption Spectra of $20 \mu \mathrm{g} \mathrm{ml}^{-1}$ of CIP ( $\square$ ), $20 \mu \mathrm{g} \mathrm{ml}^{-1}$ of MET (----) and $(1: 1)$ Mixture Containing $10 \mu \mathrm{g} \mathrm{ml}^{-1}$ of Each $(\cdots)$ Using Methanol as Blank

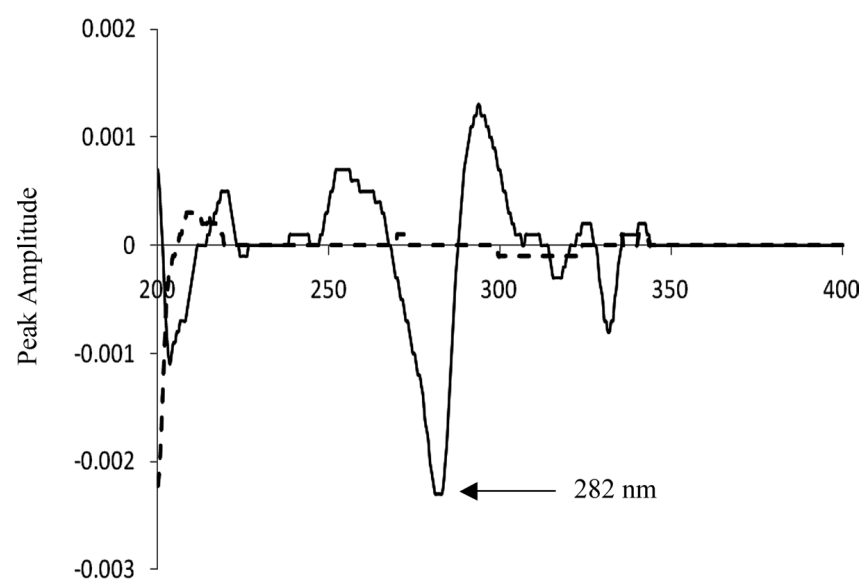

Wavelength (nm)

Fig. 3. Second Derivative Absorption Spectra of $10 \mu \mathrm{g} \mathrm{ml}^{-1} \mathrm{CIP}(-)$ and $10 \mu \mathrm{g} \mathrm{ml}^{-1}$ MET (----) in Methanol

vere overlap of the zero-order spectra of CIP and MET. In an attempt to solve this overlap, different orders of derivative spectrophotometric methods, using different solvents, were tried but first, third and fourth derivative failed to solve the overlapping problem. By applying the ${ }^{2} \mathrm{D}$ technique to the spectral data of both drugs in methanol, only CIP that could be determined in the mixture by measuring the ${ }^{2} \mathrm{D}$ value at $282 \mathrm{~nm}$ (zero ordinate value of MET). Smoothing factor is an important parameter that affects ${ }^{2} \mathrm{D}$ spectrum. By investigation, the best condition was obtained by using smoothing factor equal to 20, Fig. 3. However, the severe overlap of zero-order absorption spectra of CIP and MET made the determination of MET concentration in the mixture more difficult.

By applying the isosbestic technique, developed by Erram and Tipnis ${ }^{39)}$ MET concentration could be determined in binary mixture with CIP, without any interference. According to the isosbestic point theory, the mixture of drugs acts as a single component and gives the same absorbance value as pure drug, at the isosbestic point. This point was determined experimentally by recording the absorption spectra of 20 $\mu \mathrm{g} \mathrm{ml}^{-1}$ of each of CIP and MET, separately and that of the mixture containing equal concentrations of CIP and MET $\left(10 \mu \mathrm{g} \mathrm{ml}^{-1}\right)$, as shown in Fig. 2. This figure reveals that the mixture and each drug have different absorption spectra, 
meanwhile, they possess the same absorbance at their isosbestic point. ${ }^{38,39)}$ Therefore, by measuring the absorbance value at the chosen isosbestic point, $294.5 \mathrm{~nm}\left(A_{\text {iso }}\right)$, Fig. 2, the total concentration of both CIP and MET could be calculated $\left(C_{\mathrm{T}}\right)$. As mentioned before, the concentration of CIP $\left(C_{\mathrm{CIP}}\right)$ in the mixture could be calculated, without any interference, by measuring the ${ }^{2} \mathrm{D}$ value at $282 \mathrm{~nm}$ (zero ordinate value of MET) and thus, the concentration of MET in the mixture could be calculated by subtraction $\left(C_{\mathrm{T}}-C_{\mathrm{CIP}}\right)$.

${ }^{1}$ DD Method Preliminary investigation of the main instrumental parameters affecting the shape of derivative spectra was done. These parameters, which include smoothing factor and divisor concentration, need to be optimized to give good selectivity, high sensitivity and an adequate signal to noise ratio. ${ }^{52,53)}$ Values of smoothing factor equal to 15 and 10 were suitable for CIP and MET determination, respectively, as these values revealed a suitable signal to noise ratio and the spectra showed good resolution. Best results in terms of sensitivity were found on using either MET $\left(4 \mu \mathrm{g} \mathrm{ml}^{-1}\right)$ or CIP $\left(3 \mu \mathrm{g} \mathrm{ml}^{-1}\right)$ as divisors for CIP and MET determination, respectively. In addition, an accurate choice of working wavelengths is fundamental. The best linear response to the drug concentration was obtained by measuring the total amplitude at the minimum at $261 \mathrm{~nm}$ and the maximum at $285 \mathrm{~nm}$, for CIP determination while MET was quantified from the minimum at $295.5 \mathrm{~nm}$, as shown in Fig. 4.

Dual Wavelength Method For estimation of one component by dual wavelength method, two wavelengths were selected at which the absorbances of the other component were the same. ${ }^{43,44)}$ Therefore, the difference in absorbances in the
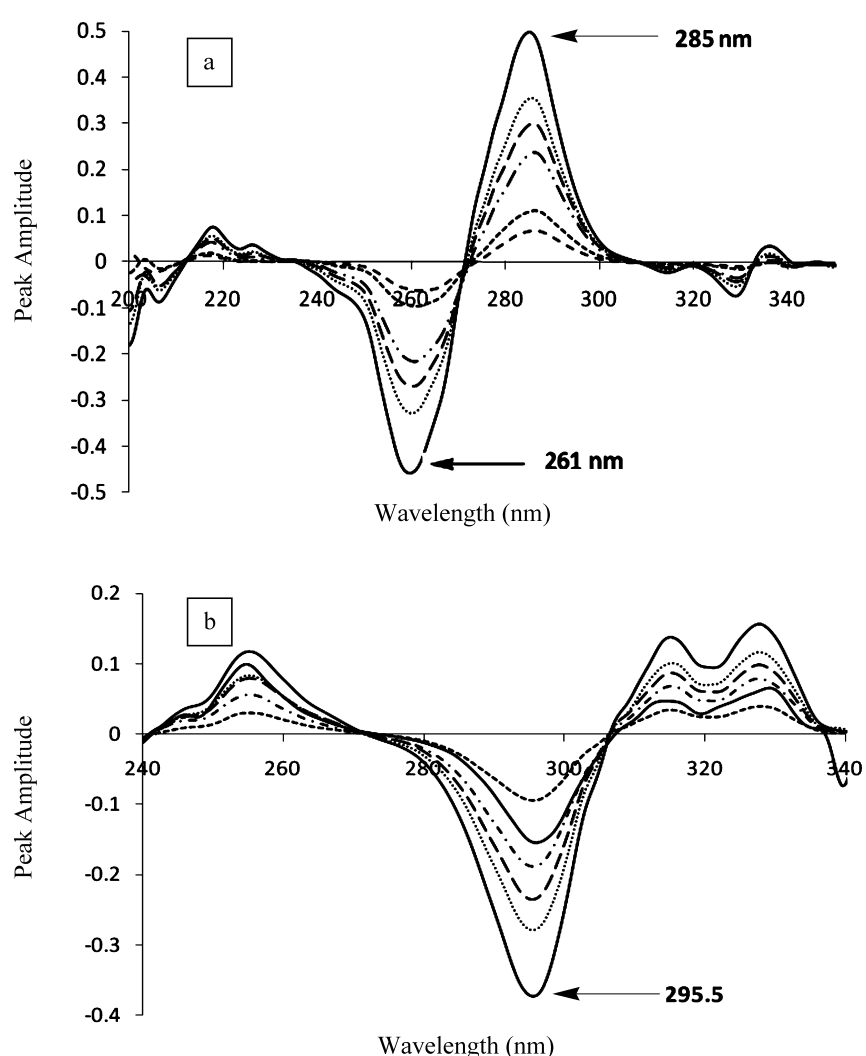

Fig. 4. First Derivative of the Ratio Spectra for Different Concentrations of CIP $\left(2.4,4,8,10,12,16 \mu \mathrm{g} \mathrm{ml}^{-1}\right)$ Using $4 \mu \mathrm{g} \mathrm{ml}^{-1}$ MET as Divisor (a) and Different Concentrations of $\operatorname{MET}\left(4,6,8,10,12,16 \mu \mathrm{g} \mathrm{ml}^{-1}\right)$ Using $3 \mu \mathrm{g} \mathrm{ml}^{-1}$ of CIP as Divisor (b) mixed spectra at corresponding wavelengths will be directly proportional to the concentration of the component of interest. As revealed in Fig. 2, the spectrum of MET shows the same absorbance at 281.5 and $335.5 \mathrm{~nm}$ (difference is zero) while that of CIP shows significant difference in absorbance, therefore, these wavelengths were selected for the determination of CIP. Similarly, the absorbances of CIP at 313 and $324 \mathrm{~nm}$ are identical, hence these two wavelengths were selected for MET determination. Calibration curves for CIP and MET were plotted between the absorbance difference at the selected wavelengths for each drug and the respective concentration. Good linearity of the two drugs was found on the concentration range of $3-16 \mu \mathrm{g} \mathrm{ml}^{-1}$ with good correlation coefficients, Table 2.

$\boldsymbol{Q}$ Analysis Method (Absorbance Ratio) The principle of this method is that for the substance that obeys Beer-Lambert law at all wavelengths, the ratio of absorptivity (or absorbance) values at any two wavelengths are constant, independent of the concentration or path length. This ratio is referred as $Q$-ratio. ${ }^{41,54)}$ One of the two selected wavelengths is an isosbestic point and the other is the wavelength of maximum absorption of one of the two components. From the overlain spectra of the two drugs and their mixture, Fig. 2, absorbances were measured at $294.5 \mathrm{~nm}$ (isosbestic point) and at $281.5 \mathrm{~nm}\left(\lambda_{\max }\right.$ of CIP) over the concentration range of $3-16 \mu \mathrm{g} \mathrm{ml}^{-1}$. Absorptivity coefficients of each drug at both wavelengths were determined and the average values were taken. The concentration of each drug in laboratory prepared mixtures and tablet formulation was determined by substituting the absorbance ratio and the absorptivity coefficients in the equations mentioned under linearity in order to develop the following sets of equations:

$$
\begin{aligned}
C_{\mathrm{CIP}} & =\frac{Q_{m}-0.5638}{2.4535-0.5638} \times \frac{A}{0.0417} \\
C_{\mathrm{MET}} & =\frac{Q_{m}-2.4535}{0.5638-2.4535} \times \frac{A}{0.0409}
\end{aligned}
$$

where $C_{\mathrm{CIP}}$ and $C_{\mathrm{MET}}$ are the concentrations of CIP and MET in $\mu \mathrm{g} \mathrm{ml}^{-1}$, respectively; $Q_{m}$ is the absorbance of sample at $\lambda_{281.5}$ /absorbance of sample at $\lambda_{294.5}$ and $A$ is the absorbance of the sample at $\lambda_{294.5}$.

Validation of ${ }^{\mathbf{2}} \mathbf{D}$, Isosbestic, ${ }^{\mathbf{1}} \mathrm{DD}$, Dual Wavelength and $\boldsymbol{Q}$ Analysis Spectrophotometric Methods The methods were validated according to $\mathrm{ICH}$ guidelines ${ }^{55)}$ for validation of analytical procedures.

Linearity The linearity of the methods was evaluated by analyzing six concentrations of each drug and each concentration was repeated three times. Linear regression equations were obtained over the concentration ranges given in Table 2. The assays were performed according to the experimental conditions previously mentioned. Table 2 also reveals the correlation coefficients along with standard deviation of the slope $\left(S_{\mathrm{b}}\right)$ and that of intercept $\left(S_{\mathrm{a}}\right)$.

Range The calibration range was established through considerations of the practical range that obeys Beer-Lambert law and the concentrations of CIP and MET present in the pharmaceutical preparation to give accurate, precise and linear results, Table 2 .

Accuracy Accuracy was determined by comparing measured concentrations of CIP and MET with the actual values. The accuracy of the results was checked by applying 


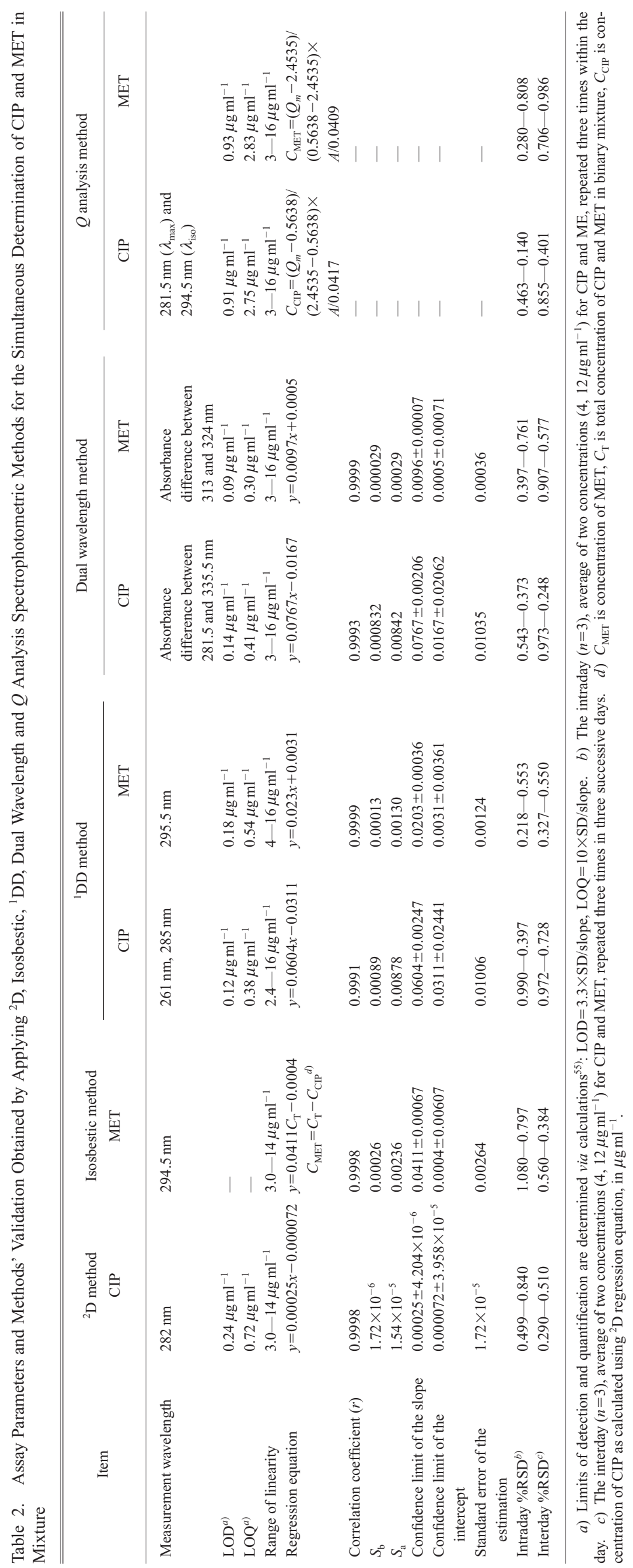


Table 3. Determination of CIP and MET in Laboratory Prepared Mixtures by the Proposed ${ }^{2} \mathrm{D}$, Isosbestic, ${ }^{1} \mathrm{DD}$, Dual Wavelength and $Q$ Analysis Spectrophotometric Methods

\begin{tabular}{|c|c|c|c|c|c|c|c|c|c|c|}
\hline \multirow{2}{*}{$\begin{array}{c}\text { Mixture } \\
\text { No. }\end{array}$} & \multicolumn{2}{|c|}{ Claimed taken $\left(\mu \mathrm{g} \mathrm{ml}^{-1}\right)$} & \multirow{2}{*}{$\frac{{ }^{2} \mathrm{D} \text { method }}{\text { Recovery }^{a)} \%}$} & \multirow{2}{*}{$\begin{array}{c}\begin{array}{c}\text { Isosbestic } \\
\text { method }\end{array} \\
\begin{array}{c}\text { Recovery } \\
\text { MET }\end{array}\end{array}$} & \multicolumn{2}{|c|}{${ }^{1} \mathrm{DD}$ method } & \multicolumn{2}{|c|}{ Dual wavelength method } & \multicolumn{2}{|c|}{$Q$ analysis method } \\
\hline & CIP & MET & & & $\begin{array}{c}\text { Recovery }^{a)} \% \\
\text { CIP }\end{array}$ & $\begin{array}{c}\text { Recovery }^{a)} \% \\
\text { MET }\end{array}$ & $\begin{array}{c}\text { Recovery }^{a)} \% \\
\text { CIP }\end{array}$ & $\begin{array}{c}\text { Recovery }^{a)} \% \\
\text { MET }\end{array}$ & $\begin{array}{c}\text { Recovery }^{a)} \% \\
\text { CIP }\end{array}$ & $\begin{array}{c}\text { Recovery }^{a)} \% \\
\text { MET }\end{array}$ \\
\hline 1 & 5 & 5 & 98.56 & 100.32 & 100.79 & 98.17 & 101.10 & 100.00 & 99.37 & 100.00 \\
\hline 2 & 7 & 7 & 101.26 & 98.40 & 101.18 & 99.44 & 99.74 & 101.64 & 99.86 & 99.82 \\
\hline 3 & 9 & 9 & 100.98 & 100.78 & 99.78 & 99.98 & 99.03 & 100.58 & 100.60 & 101.73 \\
\hline 4 & 11 & 11 & 100.80 & 101.06 & 99.30 & 100.83 & 100.72 & 101.52 & 101.73 & 101.30 \\
\hline 5 & 13 & 13 & 100.68 & 99.66 & 101.13 & 99.13 & 99.59 & 101.28 & 99.45 & 99.79 \\
\hline 6 & 15 & 15 & & & 99.90 & 99.58 & 100.40 & 101.53 & & \\
\hline Mean & & & 100.46 & 100.04 & 100.35 & 99.52 & 100.10 & 101.09 & 100.20 & 100.53 \\
\hline \pm S.D. & & & 1.08 & 1.06 & 0.790 & 0.885 & 0.776 & 0.658 & 0.983 & 0.917 \\
\hline
\end{tabular}

a) Average of three different determinations.

Table 4. Determination of CIP and MET in Ciprodiazole Tablets by ${ }^{2} \mathrm{D}$ and Isosbestic Spectrophotometric Methods and Application of the Standard Addition Technique

\begin{tabular}{|c|c|c|c|c|c|c|c|c|}
\hline & \multicolumn{4}{|c|}{${ }^{2} \mathrm{D}$ method } & \multicolumn{4}{|c|}{ Isosbestic method } \\
\hline & \multicolumn{4}{|c|}{ CIP } & \multicolumn{4}{|c|}{ MET } \\
\hline & $\begin{array}{c}\text { Claimed } \\
\left(\mu \mathrm{g} \mathrm{ml}^{-1}\right)\end{array}$ & $\begin{array}{c}\text { Recovery }^{a)} \\
\%\end{array}$ & $\begin{array}{l}\text { Pure added } \\
\left(\mu \mathrm{g} \mathrm{ml}^{-1}\right)\end{array}$ & $\begin{array}{c}\left.\text { Recovery }^{a}\right) \\
\%\end{array}$ & $\begin{array}{c}\text { Claimed } \\
\left(\mu \mathrm{g} \mathrm{ml}^{-1}\right)\end{array}$ & $\begin{array}{c}\left.\text { Recovery }^{a}\right) \\
\%\end{array}$ & $\begin{array}{c}\text { Pure added } \\
\left(\mu \mathrm{g} \mathrm{ml}^{-1}\right)\end{array}$ & $\begin{array}{c}\left.\text { Recovery }^{a}\right) \\
\%\end{array}$ \\
\hline \multirow{6}{*}{$\begin{array}{l}\text { Ciprodiazole } \\
\text { tablets }\end{array}$} & 4 & 99.20 & 3 & 98.67 & 4 & 100.55 & 3 & 99.87 \\
\hline & & & 4 & 98.00 & & & 4 & 102.18 \\
\hline & & & 6 & 98.67 & & & 6 & 101.45 \\
\hline & 6 & 98.13 & 4 & 100.00 & 6 & 99.52 & 4 & 100.25 \\
\hline & & & 6 & 100.00 & & & 6 & 100.03 \\
\hline & & & 8 & 100.50 & & & 8 & 99.95 \\
\hline Mean & & 98.67 & & 99.31 & & 100.04 & & 100.62 \\
\hline \pm S.D. & & 0.757 & & 0.904 & & 0.735 & & 0.876 \\
\hline
\end{tabular}

a) Average of three different determinations.

the proposed methods for the determination of laboratory prepared mixtures containing both drugs. The concentrations were obtained from the corresponding regression equations, results are shown in Table 3.

Accuracy of the methods was further assured by the use of the standard addition technique, which was performed by addition of known amounts of pure CIP and MET to known concentrations of the pharmaceutical preparation, the resulting mixtures were assayed and the results obtained were compared with the expected results. The good recoveries, as revealed in Tables 4 and 5 indicate good accuracy and that there is no interference from either the co-formulated drug or the frequently encountered tablet excipients.

Precision Repeatability: Two concentrations of CIP and $\operatorname{MET}\left(4,12 \mu \mathrm{g} \mathrm{ml}^{-1}\right)$ were analyzed three times, intradaily, using the proposed methods. The percentage relative standard deviation (\%RSD) was calculated, Table 2.

Reproducibility (Intermediate Precision): The previous procedure was repeated, interdaily, three times on three different days for the analysis of the two chosen concentrations of CIP and MET. \% RSD values for both drugs in all the proposed methods were ranged from 0.218 to 1.08 indicating good repeatability and reproducibility, Table 2.

Limit of Detection and Limit of Quantification Ac- cording to the $\mathrm{ICH}$ recommendations, ${ }^{55)}$ the approach based on the SD of the response and the slope was used for determining the limit of detection and limit of quantification, Table 2 .

$$
\mathrm{LOD}=3.3 \times \mathrm{SD} / \text { slope } \mathrm{LOQ}=10 \times \mathrm{SD} / \text { slope }
$$

The limits of detection obtained with the developed methods were $0.24,0.12,0.14$ and $0.91 \mu \mathrm{g} \mathrm{ml}^{-1}$ for CIP, in case of ${ }^{2} \mathrm{D}$, ${ }^{1} \mathrm{DD}$, dual wavelength and $Q$ analysis methods, respectively and $0.18,0.09$ and $0.93 \mu \mathrm{g} \mathrm{ml}^{-1}$ for MET, in case of ${ }^{1} \mathrm{DD}$, dual wavelength and $Q$ analysis methods, respectively. Therefore, the proposed ${ }^{1} \mathrm{DD}$ and dual wavelength method were found to be more sensitive than the other suggested methods, for the determination of CIP and MET, respectively.

Stability The stability of CIP and MET solutions was studied by performing the experiment and observing the change in the UV spectra compared with that of the freshly prepared solutions. In addition, an aliquot of each drug working solution was analyzed immediately and after storage for 1 week at $-4^{\circ} \mathrm{C}$, using the developed methods and the concentrations were determined. CIP and MET working solutions showed no spectrophotometric changes when stored at $-4{ }^{\circ} \mathrm{C}$ for one week. Light protected volumetric flasks were 
Table 5. Determination of CIP and MET in Ciprodiazole Tablets by ${ }^{1} \mathrm{DD}$, Dual Wavelength and $Q$ Analysis Spectrophotometric Methods and Application of the Standard Addition Technique

\begin{tabular}{|c|c|c|c|c|c|c|c|c|}
\hline & \multirow{2}{*}{\multicolumn{2}{|c|}{ Claimed $\left(\mu \mathrm{g} \mathrm{ml}^{-1}\right)$}} & \multirow{2}{*}{\multicolumn{2}{|c|}{ Pure added $\left(\mu \mathrm{g} \mathrm{ml}^{-1}\right)$}} & \multicolumn{4}{|c|}{${ }^{1}$ DD method } \\
\hline & & & & & \multicolumn{2}{|c|}{ Recovery $^{a)} \%$ of tablet } & \multicolumn{2}{|c|}{ Recovery $\left.^{a}\right) \%$ of added } \\
\hline & CIP & MET & CIP & MET & CIP & MET & CIP & MET \\
\hline \multirow{6}{*}{$\begin{array}{l}\text { Ciprodiazole } \\
\text { tablets }\end{array}$} & 6 & 6 & 4.8 & 4.8 & 101.52 & 101.17 & 99.60 & 99.00 \\
\hline & & & 6.0 & 6.0 & & 98.83 & 99.72 & \\
\hline & & & 7.2 & 7.2 & & & 101.26 & 101.08 \\
\hline & 7 & 7 & 5.6 & 5.6 & 100.73 & 101.80 & 98.71 & 99.46 \\
\hline & & & 7.0 & 7.0 & & & 98.39 & 100.00 \\
\hline & & & 8.4 & 8.4 & & & 99.87 & 99.23 \\
\hline Mean & & & & & 101.13 & 101.49 & 99.28 & 99.75 \\
\hline \pm S.D. & & & & & 0.559 & 0.445 & 0.739 & 0.742 \\
\hline
\end{tabular}

Table 5. (Continued)

\begin{tabular}{|c|c|c|c|c|c|c|c|c|}
\hline & \multicolumn{4}{|c|}{ Dual wavelength method } & \multicolumn{4}{|c|}{$Q$ analysis method } \\
\hline & \multicolumn{2}{|c|}{ Recovery $^{a)} \%$ of tablet } & \multicolumn{2}{|c|}{ Recovery $^{a)} \%$ of added } & \multicolumn{2}{|c|}{ Recovery $^{a)} \%$ of tablet } & \multicolumn{2}{|c|}{ Recovery $\left.^{a}\right) \%$ of added } \\
\hline & CIP & MET & CIP & MET & CIP & MET & CIP & MET \\
\hline \multirow{6}{*}{$\begin{array}{l}\text { Ciprodiazole } \\
\text { tablets }\end{array}$} & 99.20 & 100.87 & 99.33 & 100.04 & 100.83 & 100.54 & 99.12 & 98.81 \\
\hline & & 101.11 & 100.69 & & & 98.32 & 101.31 & \\
\hline & & & 100.52 & 100.84 & & & 100.64 & 101.07 \\
\hline & 100.06 & 101.79 & 100.09 & 101.93 & 100.87 & 100.43 & 100.50 & 99.77 \\
\hline & & & 100.04 & 99.85 & & & 99.75 & 100.03 \\
\hline & & & 98.42 & 101.07 & & & 100.07 & 99.80 \\
\hline Mean & 99.63 & 101.33 & 99.92 & 100.74 & 100.85 & 100.49 & 99.73 & 100.13 \\
\hline \pm S.D. & 0.608 & 0.651 & 0.940 & 0.751 & 0.028 & 0.078 & 0.883 & 0.924 \\
\hline
\end{tabular}

a) Average of three different determinations.

used in case of MET solutions. The concentrations obtained on day 7 were compared with that obtained on the first day of the stability testing, then the percentage concentration deviation was calculated. For acceptance criterion of stability, the deviation of the measured concentrations of the stored samples compared to the freshly prepared samples should be within $\pm 15 \%{ }^{55)}$

Optimization and Validation of Partial Least-Squares (PLS) Method In chemometric-assisted spectrophotometric methods, the quality of multicomponent analysis is dependent on the wavelength range and spectral mode used. ${ }^{56)}$ The wavelength range $280-330 \mathrm{~nm}$ in the intervals with $\Delta \lambda=0.2 \mathrm{~nm}$ was chosen as it was providing the greatest amount of information about the mixture components. Despite PLS procedures are designated to be full spectrum computational procedures; however, using highly noisy, scarcely informative wavelengths detracts from precision. This can be lessened, by discarding particularly noisy wavelengths which, in our case, are the range less than $280 \mathrm{~nm}$ and more than $330 \mathrm{~nm}$. Selection of the optimum number of principle components was a very important step before constructing the PLS model. If the number of factors retained was more than the required, more noise would be added to the data. On the other hand, if the number retained was less than the required, meaningful data that could be necessary for the calibration might be ignored. The selected model was that with the smallest number of factors such that RMSECV for that model was not significantly greater than RMSECV from model with an additional factor. Three factors were found
Table 6. Results Obtained for the Determination of CIP and MET in Synthetic Mixtures by Using PLS Technique

\begin{tabular}{|c|c|c|c|c|}
\hline \multirow{2}{*}{ Sample No. } & \multicolumn{2}{|c|}{ Claimed taken $\left(\mu \mathrm{g} \mathrm{ml}^{-1}\right)$} & \multicolumn{2}{|c|}{ Recovery \% } \\
\hline & CIP & MET & CIP & MET \\
\hline 1 & 2 & 2.0 & 99.55 & 99.77 \\
\hline 2 & 4 & 4.0 & 100.72 & 97.79 \\
\hline 3 & 6 & 5.8 & 98.94 & 100.25 \\
\hline 4 & 6 & 6.0 & 100.10 & 99.87 \\
\hline 5 & 7 & 6.8 & 99.07 & 101.02 \\
\hline 6 & 7 & 7.0 & 97.02 & 102.34 \\
\hline Mean & & & 99.23 & 100.17 \\
\hline \pm S.D. & & & 1.27 & 1.51 \\
\hline
\end{tabular}

suitable for PLS model. Visual inspection was used for determining the optimum number of factors. ${ }^{57)}$ The external validation of PLS models was achieved by evaluation of the prediction ability of the PLS model to a prediction set of 6 new laboratory prepared binary mixtures, different from those of the calibration set. The concentrations of CIP and MET were falling within the ranges of calibration matrix. Satisfactory results were obtained, Tables 6 and 7, indicating the high selectivity of the proposed method for simultaneous determination of CIP and MET in laboratory prepared mixtures and in tablet form.

Statistical Analysis The proposed methods were compared using statistical analysis, where three different ciprodiazole samples were determined simultaneously by ${ }^{2} \mathrm{D}$, isos- 
Table 7. Determination of CIP and MET in Ciprodiazole Tablets by PLS Method and Application of the Standard Addition Technique

\begin{tabular}{|c|c|c|c|c|c|c|c|c|}
\hline & \multicolumn{2}{|c|}{ Claimed $\left(\mu \mathrm{g} \mathrm{ml}^{-1}\right)$} & \multicolumn{2}{|c|}{ Pure added $\left(\mu \mathrm{g} \mathrm{ml}^{-1}\right)$} & \multicolumn{2}{|c|}{ Recovery $^{a)} \%$ of tablet } & \multicolumn{2}{|c|}{ Recovery $\left.^{a}\right) \%$ of added } \\
\hline & CIP & MET & CIP & MET & CIP & MET & CIP & MET \\
\hline \multirow{5}{*}{$\begin{array}{l}\text { Ciprodiazole } \\
\text { tablets }\end{array}$} & 1 & 1 & 6 & 6 & 97.26 & 99.52 & 100.20 & 99.57 \\
\hline & 2 & 2 & 5 & 5 & 98.75 & 100.28 & 101.05 & 99.84 \\
\hline & 3 & 3 & 1 & 1 & 98.34 & 98.37 & 99.84 & 101.01 \\
\hline & 4 & 4 & 2 & 2 & 99.11 & 99.27 & 98.42 & 100.14 \\
\hline & 5 & 5 & 3 & 3 & 97.75 & 99.52 & 100.02 & 100.91 \\
\hline Mean & & & & & 98.24 & 99.39 & 99.91 & 100.29 \\
\hline \pm S.D. & & & & & 0.75 & 0.69 & 0.95 & 0.64 \\
\hline
\end{tabular}

a) Average of three different determinations.

Table 8. One-Way ANOVA Testing for the Different Proposed Methods Used for the Determination of CIP and MET in Tablet Form

\begin{tabular}{clrrr}
\hline \hline & Source of variation & Degree of freedom & Sum of squares & Mean square \\
& Between experiment & 4 & 4.782 & 1.195 \\
CIP & Within experiment & 10 & 4.568 & 0.457 \\
& Between experiment & 4 & 4.093 & 1.023 \\
& Within experiment & 10 & 4.223 & 0.422 \\
\hline
\end{tabular}

bestic, ${ }^{1} \mathrm{DD}$, dual wavelength and $Q$ analysis spectrophotometric methods and PLS chemometric method. Each sample was analyzed in duplicate, then, one-way ANOVA test was applied. The calculated $F$ value is less than the tabulated one (3.48) at $p<0.05$, indicating that there is no significant difference between the proposed methods with respect to accuracy and precision. Results are given in Table 8.

\section{Conclusion}

The proposed ${ }^{2} \mathrm{D}$, isosbestic, ${ }^{1} \mathrm{DD}$, dual wavelength and $Q$ analysis spectrophotometric and PLS chemometric techniques allowed the resolution of binary mixture of CIP and MET with satisfactory results. Dual wavelength, $Q$ analysis and chemometric methods, as the applied PLS, have the advantage of eliminating the derivative steps. The proposed methods are simple, rapid, sensitive and precise and could be easily applied in quality control laboratories for the simultaneous determination of the cited drugs in pure and tablets forms, without any preliminary separation step. Furthermore, they are economic in comparison to the more time consuming chromatographic techniques often used for the assay of formulations. The suggested methods were validated as per ICH guidelines.

\section{References}

1) Kumar P., Clark M., "Clinical Medicine," 6th ed., Elsevier, Amsterdam, 2005.

2) Sweetman S. C., "Martindale, The Complete Drug Reference," 35th ed., The Pharmaceutical Press, London, Chicago, 2007.

3) Block J. H., Beale J. M., "Wilson and Gisvold's Textbook of Organic Medicinal and Pharmaceutical Chemistry," 11th ed., Lippincott Williams \& Wilkins, Philadelphia, 2004.

4) Werk R., Schneider L., Infection, 16, 257-260 (1988).

5) Fratini L., Schapoval E. E. S., Int. J. Pharm., 127, 279-282 (1996).

6) Mostafa S., El-Sadek M., Alla E. A., J. Pharm. Biomed. Anal., 27, $133-142$ (2002).

7) Nagaralli B. S., Seetharamappa J., Melwanki M. B., J. Pharm. Biomed. Anal., 29, 859-864 (2002).

8) Pascual-Reguera M. I., Parras G. P., Daz A. M., Microchem. J., 77, 79-84 (2004).

9) Veiopoulou C. J., Ioannou P. C., Lianidou E. S., J. Pharm. Biomed. Anal., 15, 1839-1844 (1997).
10) Navalón A., Ballesteros O., Blanc R., Vílchez J. L., Talanta, 52, 845852 (2000).

11) Tong C., Zhuo X., Guo Y., Fang Y., J. Lumin., 130, 2100-2105 (2010).

12) Thoppil S. O., Amin P. D., J. Pharm. Biomed. Anal., 22, 699-703 (2000).

13) Maya M. T., Gonçalves N. J., Silva N. B., Morais J. A., J. Chromatogr. B: Biomedical Sciences and Applications, 755, 305-309 (2001).

14) Zotou A., Miltiadou N., J. Pharm. Biomed. Anal., 28, 559-568 (2002).

15) Imre S., Dogaru M. T., Vari C. E., Muntean T., Kelemen L., J. Pharm. Biomed. Anal., 33, 125-130 (2003).

16) Vybíralová Z., Nobilis M., Zoulova J., Květina J., Petr P., J. Pharm. Biomed. Anal., 37, 851-858 (2005).

17) Bannefeld K. H., Stass H., Blaschke G., J. Chromatogr. B: Biomedical Sciences and Applications, 692, 453 - 459 (1997).

18) Michalska K., Pajchel G., Tyski S., J. Chromatogr. A, 1051, 267—272 (2004).

19) Novakovic J., Nesmerak K., Nova H., Filka K., J. Pharm. Biomed. Anal., 25, 957-964 (2001).

20) Reinscheid U. M., J. Pharm. Biomed. Anal., 40, 447-449 (2006).

21) Sousa J., Alves G., Fortuna A., Pena A., Lino C., Falcão A., Biomed. Chromatogr., 25, 535-541 (2011).

22) Grondin C., Zhao W., Fakhoury M., Jacqz-Aigrain E., Biomed. Chromatogr., 25, 827-832 (2011).

23) Nagaraja P., Sunitha K. R., Vasantha R. A, Yathirajan H. S., J. Pharm. Biomed. Anal., 28, 527-535 (2002).

24) Saffaj T., Charrouf M., Abourriche A., Abboud Y., Bennamara A., Berrada M., Il Farmaco, 59, 843-846 (2004).

25) Saffaj T., Charrouf M., Abourriche A., Aboud Y., Bennamara A., Berrada M., Dyes Pigm., 70, 259-262 (2006).

26) El-Ghobashy M. R., Abo-Talib N. F., J. Advert. Res., 1, 323-329 (2010).

27) Galmier M. J., Frasey A. M., Bastide M., Beyssac E., Petit J., Aiache J. M., Lartigue-Mattei C., J. Chromatogr. B Analyt. Technol. Biomed. Life Sci., 720, 239-243 (1998).

28) Akay C., Özkan S. A., Şentürk Z., Cevheroğlu Ş., Il Farmaco, 57, 953-957 (2002).

29) Bempong D. K., Manning R. G., Mirza T., Bhattacharyya L., J. Pharm. Biomed. Anal., 38, 776-780 (2005).

30) Mishal A., Sober D., J. Pharm. Biomed. Anal., 39, 819-823 (2005).

31) Sagan C., Salvador A., Dubreuil D., Poulet P. P., Duffaut D., Brumpt I., J. Pharm. Biomed. Anal., 38, 298-306 (2005).

32) Tavakoli N., Varshosaz J., Dorkoosh F., Zargarzadeh M. R., J. Pharm. Biomed. Anal., 43, 325-329 (2007).

33) Vega E., Solá N., J. Pharm. Biomed. Anal., 25, 523-530 (2001).

34) Vega E., Dabbene V., Nassetta M., Solá N., J. Pharm. Biomed. Anal., 
21, $1003-1009$ (1999).

35) ElKady E. F., Mahrouse M. A., Chromatographia, 73, 297-305 (2011).

36) Salinas F., Nevado J. J., Mansilla A. E., Talanta, 37, 347-351 (1990).

37) Morelli B., J. Pharm. Biomed. Anal., 32, 257-267 (2003).

38) Ramadan N. K., Mohamed H. M., Moustafa A. A., Bull. Fac. Pharm. Cairo Univ., 47, 35-47 (2009).

39) Erram S. V., Tipnis H. P., Indian Drugs, 31, 65-68 (1994).

40) Vikas J., Rajesh S., J. Appl. Chem. Res., 5, 48-56 (2008).

41) Bhusari K. P., Khedekar P. B., Dhole S., Banode V. S., Indian J. Pharm. Sci., 71, 505-508 (2009).

42) Ramesh D., Ramakrishna S., Int. J. Pharm. Pharm. Sci., 2, 215-219 (2010).

43) Choudhari V. P., Suryawanshi V. M., Mahabal R. H., Deshchougule S. G., Bhalerao K. P., Kuchekar B. S., Int. J. Pharm. Sci. Rev. Res., 3, $73-76$ (2010).

44) Abdelwahab N. S., Arab. J. Chem. (2011), article in press.

45) Khajehsharifi H., Eskandari Z., Asadipour A., Drug Test. Anal., 2, $162-167$ (2010)

46) Hegazy M. A., El-Ghobashy M. R., Yehia A. M., Mostafa A. A., Drug
Test. Anal., 1, 339-349 (2009).

47) Thomas E. V., Haaland D. M., Anal. Chem., 60, 1193-1202 (1988).

48) Martens H., Naes T., "Multivariate Calibration," Wiley, Chichester, 1989.

49) Galeano Diaz T., Durán Merás I., Guiberteau Cabanillas A., Alexandre Franco M. F., Anal. Chim. Acta, 511, 231-238 (2004).

50) Ni Y., Gong X., Anal. Chim. Acta, 354, 163-171 (1997).

51) El-Gindy A., Il Farmaco, 60, 745-753 (2005).

52) Berzas Nevado J. J., Guiberteau Cabanillas C., Salinas López F., Anal. Lett., 23, 2077-2094 (1990).

53) Morelli B., Talanta, 41, 673 - 683 (1994).

54) Beckett A. H., "Practical Pharmaceutical Chemistry," 4th ed., Part Two, CBS Publishers and Distributers, India, 1997.

55) "Q2 (R1) Validation of Analytical Procedures, Proceedings of the International Conference on Harmonisation (ICH)," Commission of the European Communities, Geneva, 1996.

56) Blanco M., Coello J., Gonzalez F., Iturriaga H., Maspoch S., J. Pharm. Sci., 82, 834-837 (1994).

57) Espinosa-Mansilla A., Pena A. M., Martínez-Galera M., Salinas F., Anal. Chim. Acta, 276, 141-149 (1993). 